\title{
Insight
}

\section{Are We Entering an Era of Concatenated Global Crises?}

\author{
$\underline{\text { Duan Biggs }}^{1}, \underline{\text { Reinette (Oonsie) Biggs }}^{2}$, Vasilis Dakos $^{3}, \underline{\text { Robert J. Scholes }}^{4}$, and Michael Schoon $^{5}$
}

\begin{abstract}
An increase in the frequency and intensity of environmental crises associated with accelerating human-induced global change is of substantial concern to policy makers. The potential impacts, especially on the poor, are exacerbated in an increasingly connected world that enables the emergence of crises that are coupled in time and space. We discuss two factors that can interact to contribute to such an increased concatenation of crises: (1) the increasing strength of global vs. local drivers of change, so that changes become increasingly synchronized; and (2) unprecedented potential for the propagation of crises, and an enhanced risk of management interventions in one region becoming drivers elsewhere, because of increased connectivity. We discuss the oil-food-financial crisis of 2007 to 2008 as an example of a concatenated crisis with origin and ultimate impacts in far removed parts of the globe. The potential for a future of concatenated shocks requires adaptations in science and governance including (a) an increased tolerance of uncertainty and surprise, (b) strengthening capacity for early detection and response to shocks, and (c) flexibility in response to enable adaptation and learning.
\end{abstract}

Key Words: concatenation; connectivity; crisis; disaster; food price crisis; governance; learning; thresholds

\section{INTRODUCTION}

The risk of an escalation in number and intensity of crises arising from accelerating human-induced global change is an issue of substantial concern to policy makers (MA 2005, IPCC 2007, Battisti and Naylor 2009, Rockström et al. 2009). In particular, there is evidence to suggest that large magnitude disturbances may become increasingly coupled in time and space, leading to concatenated global crises (MA 2005, Adger et al. 2009, Rockström et al 2009). An escalation in global shocks, and particularly concatenated global shocks, are likely to have especially large impacts on the world's poor and jeopardize efforts to substantively reduce global poverty in the 21st century (WRI 2008, UNDP 2010, World Bank 2010).

Disasters such as recent flooding in Pakistan and China, unprecedented fires in Russia, and hurricane Katrina, which had damage costs of over US\$250 Billion (Comfort 2005), are recent examples of 'natural disasters' that particularly affected the poor. There is now substantial evidence that the frequency of such events is likely to increase because of human-induced global change, including climate change, land-cover conversion, and increased global connectivity (MA 2005, IPCC 2007). If such events also become more concatenated, their impacts are likely to be worsened. For instance, the impacts of recent flooding in northeastern Australia increased vulnerability of affected areas to the impacts of cyclone Yasi.

Growing global connectivity increases the potential for crises to spread, synchronize, and interact in novel ways as social-ecological systems (SESs) around the world become increasingly connected (Young et al. 2006, Peters et al. 2008). The global number of internet users grew by $362 \%$ from 360 million in 2000 to 1.67 billion in 2009 (International Telecommunications Union 2009), and has been an important factor in the spread of political dissent, for example in North Africa. International tourism arrivals grew from 25 million in 1950 to just under 700 million in 2002, and over 900 million in 2007 (World Tourism Organization 2008), but then

\footnotetext{
${ }^{1}$ ARC Centre of Excellence for Coral Reef Studies, James Cook University, Townsville Australia, ${ }^{2}$ Stockholm Resilience Centre, Stockholm University, Sweden, ${ }^{3}$ Department of Aquatic Ecology \& Water Quality Management, Wageningen University, ${ }^{4} \mathrm{CSIR}$ Natural Resources and the Environment, Pretoria, South Africa, ${ }^{5}$ School of Human Evolution and Social Change, Arizona State University
} 
dropped worldwide during the 2008 financial crisis. In biotic systems, the spread of alien invasive species is accelerating (McGeogh et al. 2010), particularly in association with increased movement of goods and people around the globe.

This paper provides a synthetic summary of the mechanisms through which large magnitude disturbances are increasingly coupled in time and space, leading to concatenated crises. Concatenated crises are disturbances, i.e., shocks, that emerge near simultaneously, spread rapidly, and interact with each other across the globe. We analyze the food price crisis of 2008, an interaction between the oil price spike of 2007, pro-biofuel policies, and reactionary protectionism, as an example of a globally coupled crisis in which origin and effects stemmed from far removed parts of the world and diverse economic sectors, and particularly affected the poor. Finally, we discuss recent advances in resilience thinking, specifically how advances in detecting regime shifts and in governance thinking can build resilience to concatenated crises.

\section{MECHANISMS FOR CONCATENATED CRISES}

Two mechanisms may lead to enhanced concatenation of crises. First, global drivers are becoming increasingly dominant over local drivers as determinants of the dynamics of SESs. This increases pressures experienced by a SES; many failures are attributed to 'multiple stresses,' acting additively or even multiplicatively. Importantly, it also leads to synchronous changes across systems in different parts of the globe, increasing the scale of disasters. Second, increased connectivity can enable local disturbances to propagate faster, turning local disasters into global crises. Increased connectivity also means there is a higher risk of management responses in one system unintendedly precipitating undesirable change in far removed systems.

\section{Powerful global-scale drivers}

Global-scale processes are increasingly important drivers of change. Examples include climate change (IPCC 2007), ocean acidification (Orr et al. 2005), invasive species (McGeogh et al. 2010), pandemics such as the extinction of amphibians due to the Chytrid fungus (Berger et al. 1998), and the globalization of agricultural commodity markets (Adger et al 2009). Global drivers on their own, or in combination with local drivers, can put sufficient pressure on local ecosystems to result in collapse of the delivery of local ecosystem services on which the poor often directly depend. For example, increasing temperatures and lower rainfall thought to be associated with global-scale greenhouse gas emissions add extra pressure to ecosystems in southeastern Australia (Murphy and Timbal 2008) that have already suffered extensive degradation due to local pressures. These combined global and local-scale pressures have jeopardized commercial crop production and water quality in several areas and led to bankruptcy of farmers (Pengelly and Fishburn 2002).

\section{Propagation of shocks and management responses through increasing global connectivity}

Increased connectivity enables local-scale processes to propagate upward, generating impacts at continental to global scales (Peters et al. 2008). Disease epidemics are especially sensitive to connectivity. The spread of bubonic plague ('Black Death') in the 14th century was by local spatial diffusion, which effectively confined it to Europe. In contrast, growing connectivity in the age of air travel means that disease epidemics that previously might have died-out locally are now propagated around the globe, as in the case of the SARS and H1N1 outbreaks (Fraser et al. 2009, Vespignani 2009). Thus, if global pandemics are to be contained in the modern era, a highly effective system of early disease detection and rapid response is required.

Socioeconomic systems are also susceptible to rapid contagion. The potential for the propagation of crises to distant SESs can, on their own, or in combination with global and local pressures push those systems below a critical level of service delivery. For example, the global financial crisis of 2008 propagated from failures in the U.S. housing market to the banking sector in the developed world, ultimately affecting availability of credit globally and impacting the poor in both developed and developing regions. In particular, although this crisis primarily affected banking sectors in high income countries, it substantially exacerbated levels of unemployment and poverty in low and middle income countries (Brunnermeier 2009, McCawley 2009, World Bank 2009). 
Greater connectivity and enhanced feedbacks between systems furthermore increases risk that management responses in one region become drivers of change in others. As impacts of global drivers and propagated disturbances increase, decision makers take action to mitigate the impacts of these crises in their constituencies. In a highly coupled world, actions in one region may add pressures to systems in other regions and create, or contribute to, crisis conditions elsewhere. For example, Adger et al. (2009) show how incentives for increased coffee production in Vietnam had the intended effect of increased well-being for some in Vietnam, but led to a reduction in global coffee prices, decreasing livelihood security of communities dependent on coffee production in Mexico.

\section{THE FOOD PRICE CRISIS: CONCATENATION AT WORK}

The food price crisis of 2007 to 2008 is an excellent example of how policy responses by individual countries, combined with powerful global drivers in highly coupled systems, ultimately affected the entire globe. Between 2004 and 2008, the price of staples such as rice increased by $255 \%$ and wheat by $81 \%$ before falling again (Fig. 1; Headey and Fan 2008). The increased food prices resulted in effective food shortages, as poorer people were no longer able to afford food, and to food riots in a number of countries (Fig. 2), ultimately affecting over 100 million people worldwide. Prior to 2004, the real prices of staple foods had declined for nearly three decades and were at an all-time low (Headey and Fan 2008). However, from 2004 to 2008, the price of petroleum, coal, and natural gas increased by an average of $127 \%$ (Headey and Fan 2008). Energy forms a large component of food production and transport costs. In 2003, the EU enacted probiofuel production policies (the USA followed in 2005), partly in response to the rising energy price, but also in response to security concerns and to some extent to mitigate climate change. From 2007 to 2008 , the resulting conversion of land from food to biofuel production exacerbated inflationary pressure on global food prices, already higher from increasing energy and fertilizer costs. Some authors also point to the effect of droughts in key production regions in reducing food supplies as an additional cause of the price escalation (Garber 2008, Mitchell 2008). In dealing with the emerging food price crisis, a number of countries, starting with India but ultimately including Egypt, Vietnam, Argentina,
Russia, India, and China, enacted food export restrictions, bans, and taxes, which further restricted food supply and exacerbated price increases at the global scale (Beattie 2008). For rice in particular, the export bans played a major role in the upsurge in price (Headey and Fan 2008). Moreover, globally connected financial markets have allowed the development of commodity derivatives including food. Investments in commodity derivatives are used as a hedge because returns in the commodity sector are relatively uncorrelated with returns to other assets (FAO 2010). Although commodity derivatives were not the cause of the food price crisis, the derivative markets have probably amplified price volatility (Headey and Fan 2008, FAO 2010).

The food price crisis illustrates how a series of concatenated global crises interacted with different policy responses in a diverse range of countries to propagate the crisis throughout a highly connected global system. Rising energy prices were the global driver that underpinned the crisis. The nationalscale pro-biofuel policies, a policy response from powerful high income countries, contributed to the increase of food prices globally. Food export restrictions were a response by decision makers in middle and low income countries to try to avert crises within their constituencies. However, the highly coupled nature of global food markets resulted in drastic price increases because of the export restrictions. The result was food shortages and riots in many low income countries in the Caribbean, Africa, and Asia (Fig. 2).

The food price crisis also illustrates how vulnerable low income communities are often most seriously affected by global crises. The population groups most vulnerable to higher food prices are those that spend a large proportion of their income on food, and have few coping strategies on which to rely (Brinkman et al. 2009, Yngve et al. 2009). The 2007-2008 food price crisis was followed shortly by the global financial crisis that reduced exports, economic growth, levels of employment, and government budgets for social support in many low and middle income countries (Brinkman et al. 2009). Although food prices dropped as a result of financial crisis, the Food and Agriculture Organization's Cereal Price Index was still 50\% higher in January 2009 than in 2005. Simulations suggest that an additional 457 million people are therefore at risk of hunger and malnutrition (Brinkman et al. 2009). 
Fig. 1. International prices of rice and wheat from 1983 to 2008 per ton in US\$ and timeline of key events in the food price crisis (Headey and Fan 2008, IRRI 2010).

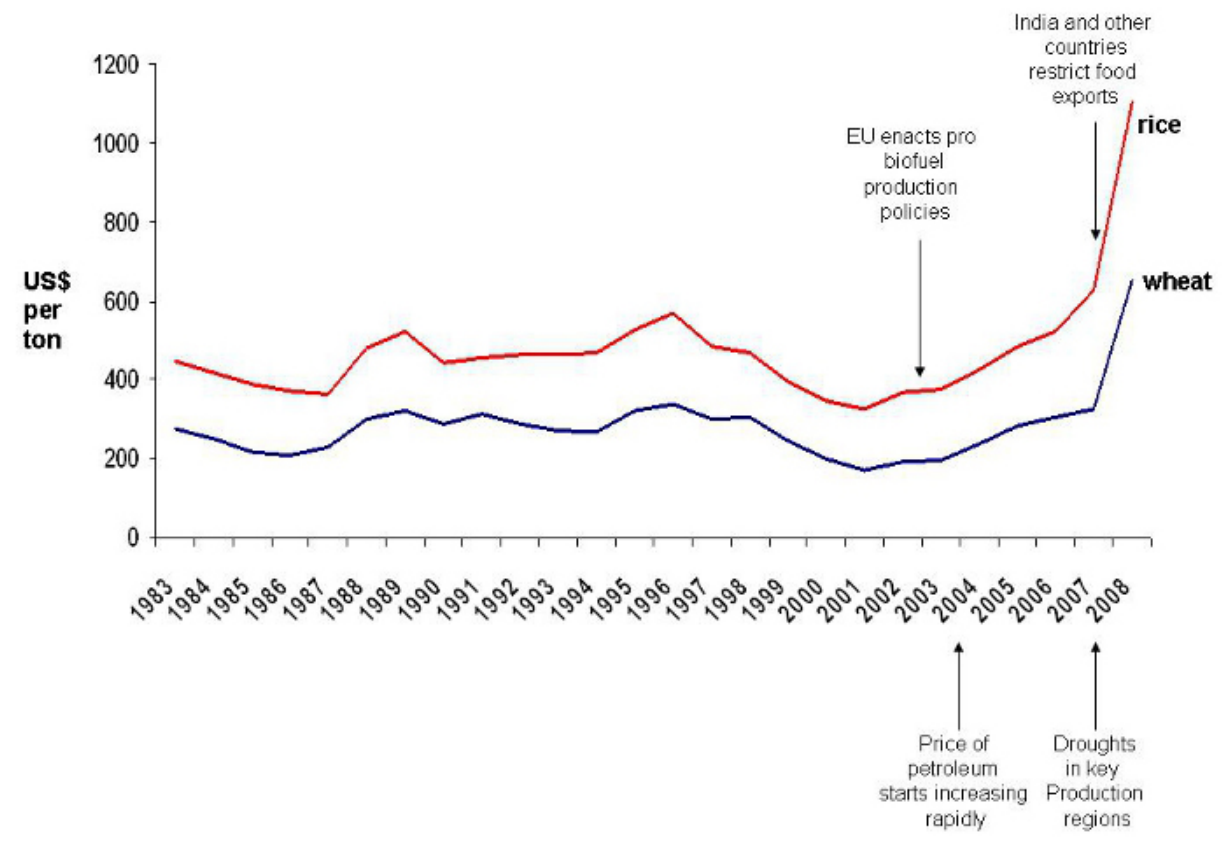

\section{COMPOUNDING EFFECTS AND NOVEL CRISES}

Agricultural production provides a good example of how humans aim to suppress natural variation, for example in water availability and pest outbreaks, to create a stable environment for economic activity. The tendency to reduce natural variation in a highly connected world creates further possibilities for the emergence of entirely novel crises.

\section{The compounding effect of suppressing natural variation}

Humanity's tendency to damp down natural variation can reduce the buffering capacity of SESs to shocks. The policy of suppressing small wildfires, for instance in the western USA and southeast Australia, has led to large, high-impact conflagrations because of the build-up of fuel (Minnich 2001, Janssen et al. 2004). Repeated insecticide application has been associated with periodic outbreak of insect plagues (Ludwig et al. 1978). This is because ecosystem components and suites of species that are adapted to extreme values of environmental conditions are competitively disadvantaged when those conditions are not experienced, and are progressively lost from the system. Hence, in the first example, plant communities become dominated by nonfire adapted species, which are overwhelmed by the intensity of the eventual fire. In the second example, when insecticides fail, the natural mechanisms that limit insect outbreaks are no longer effective. In an analogous case, the canalization and structural modification of river systems have increased the amplitude and frequency of severe floods as the natural buffering capacity against floods is reduced or removed (Criss and Shock 2001). Paradoxically, we tame the environment to promote stability but this taming may sow the seeds for later larger crises. The reduced buffering capacity of SESs to shocks increases the risk of transgressing dangerous thresholds; increased connectivity then propagates the failure elsewhere.

\section{The emergence of novel crises}

The food price crisis was a global emergency that stemmed from powerful global drivers, high levels of connectivity, and reactive national policies. We may be able to predict, and mitigate against, the re- 
Fig. 2. The interactive effects of global drivers and national-scale policy responses led to the food price crisis of 2007 to 2008 with origins and impacts in far removed regions and sectors of the globe. The crisis was exacerbated by droughts in key production regions.

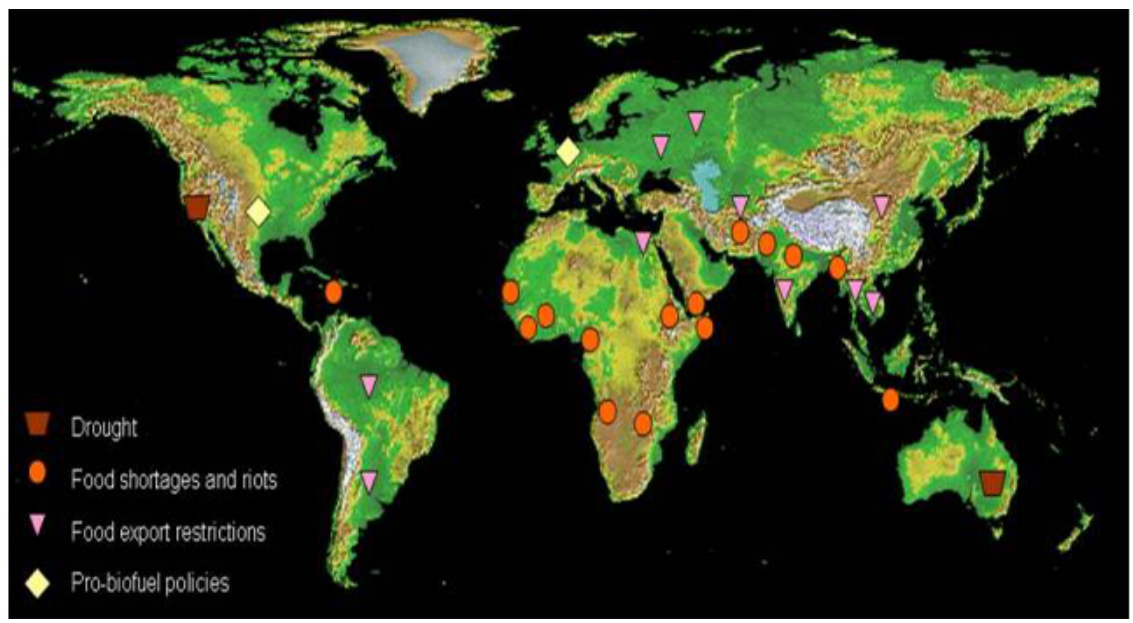

emergence of similar crises. However, complex systems of interdependent networks can also behave in unexpected ways leading to outcomes that are difficult, or close to impossible, to predict (Vespignani 2009, Buldyrev et al. 2010). In addition, it is very challenging to detect the approach of a critical threshold in a SES without actually crossing it (Biggs et al. 2009, Scheffer et al. 2009). Timely and accurate prediction of large-scale system collapses resulting from concatenated crises, in which the transgression of critical thresholds, interconnectivity, and reduced buffering capacity to shocks interact, may be beyond our capacity, and once they emerge, our response strategies may be inadequate for such unprecedented situations.

\section{ADVANCING UNDERSTANDING OF CONCATENATED CRISES}

How can humanity deal with the uncertainty implicit in an era of novel concatenated crises? We propose the following research areas to further our understanding:

- Which local systems are particularly vulnerable to the pressures imposed by global drivers?

- Which thresholds may exist at regional to global-scale (planetary boundaries, sensu
Rockström et al. 2009) that may lead to propagating crises?

- Under what circumstances are the effects of crossing local-scale thresholds likely to propagate upward and outward, because of connectivity and interdependence?

- What types of management response at local and regional scales are likely to have undesirable consequences for other regions?

- What types of actions can contain the spread of shocks once they occur (sensu Vespignani 2009), and at what scales are they effective?

The answers to these questions are currently unclear, except in unhelpfully general terms. Some of the uncertainty may be reducible through research and by applying advances in network theory and analysis (e.g., Buldyrev et al. 2010) and web-based tools for monitoring (e.g., Galaz et al. 2010). However, other aspects of the uncertainty surrounding concatenated crises are probably irreducible, because they result from fundamentally unpredictable processes. As society increasingly confronts such situations, there is a need to evolve responses suited to the realities of complex systems.

Humanity needs to learn to live within dynamic, diverse, and interconnected systems. Society's ability to deal with crises will be enhanced by our 
capacity to learn from experiences elsewhere and in the past (Pahl-Wostl 2006, Chapin et al. 2010). For example, awareness of the consequences of government inaction during the Great Depression of 1929 to 1933 enabled a concerted policy response by governments during the recent financial crisis (Wolf 2009). The EU's reduction in incentives for biofuels in response to the 2007-2008 food price crisis is another example of adaptive learning. Similarly, an increased tolerance of noncrisis level variation in SESs can reduce the risk of collapse when a system is exposed to larger shocks. Moreover, successfully coping with small disturbances has been shown to increase the resilience of individuals, organizations, and communities to later crises (van Praag 2003, Cioccio and Michael 2007).

Recent developments in understanding how systems behave when they are close to transitions may offer new tools in dealing with the increased potential of unexpected changes. There is evidence of a variety of statistical signals prior to critical transitions (Scheffer et al. 2009). Systems close to a threshold appear increasingly volatile (Carpenter and Brock 2006) and correlated (Ives 1995), both in time (Held and Kleinen 2004) and in space (Dakos et al. 2010). Although these signals do not provide the precise location of a threshold, they do give an indication of the proximity to a regime shift (van Nes and Scheffer 2007).

The same increased connectivity that promotes the concatenation of crises also provides unprecedented opportunities to learn about emerging problems and coordinate a response. For example, the World Health Organization uses web-crawlers to collect data that can help detect the outbreak of an epidemic (Weir and Mykhalovskiy 2006). Similar approaches can be combined with the early warning methods mentioned above, to provide tools that may prevent the spread of concatenated crises in ecosystems and SESs (Galaz et al. 2010).

\section{GOVERNANCE OF CONCATENATED CRISES}

There is increasing evidence that a polycentric approach to governance builds adaptive capacity and creates more robust institutional arrangements to unexpected disturbances (Anderies et al. 2007, Ostrom 2010). In a polycentric approach, multiple governing bodies at a variety of scales have jurisdiction over specific issues and geographic regions (Ostrom et al. 1961). The combination of autonomy and the interaction with other governing bodies provides opportunities for experimentation and learning across multiple issues, arenas, and scales. Multiple independent governance arrangements provide both a diversity of approaches to a crisis and the redundancy to recover in cases of failure (Folke et al. 2005). Such flexibility and opportunities for learning contrast with top-down bureaucratic structures, designed to minimize change. Building networks of organizations committed to a process of continual inquiry, informed action, and adaptive learning is a more flexible and more robust strategy to cope with disasters than the standard practice of establishing greater control over possible threats through inward focused administrative structures (Comfort 2005).

However, polycentric systems of governance, while improving the capacity for experimentation and learning, still require two further shifts from traditional governance models for effective response to increasingly complex crises. The first shift requires individual jurisdictions to take advantage of the findings from across a polycentric system and allow for adaptive policy making. Decision makers, whether bureaucrats or businesspeople, politicians or the public, too often retain a perspective that views experimentation and revision based on new information as an acknowledgement of error and poor judgment, rather than as the only means of working through complex, nearly intractable problems. The second shift requires a diagnostic approach to governance (Ostrom 2007). Similar to diagnostics in medicine, this approach systematically looks at a framework comprised of large numbers of relevant variables that affect patterns of interaction and outcome for a situation without necessarily analyzing every causal relationship. Instead, in response to living in an ever changing complex system that is only incompletely understood, the focus is on ongoing analysis, experimentation, and adaptation rather than on finding ideal solutions and one-stop fixes.

In conclusion, we argue that the interaction of strong global drivers, increased potential for the propagation of disturbances across systems, and the heightened likelihood of policy responses in one region affecting other regions can lead to a concatenation of crises. Scientific capacity for the early detection of dangerous and potentially propagating crises needs to be advanced, as does 
understanding and awareness of feedbacks and interdependencies that can lead to impacts spreading to other systems. Globally coherent strategies for the management of large crises, supported by a mind-set that uses crises as an opportunity for learning, are required.

Responses to this article can be read online at: http://www.ecologyandsociety.org/voll6/iss2/art27/ responses/

\section{Acknowledgments:}

This paper was generated from discussions at the Resilience Alliance Young Scientists (RAYS) meeting in Stockholm in 2008, followed by a smaller workshop in Madison, Wisconsin. We would like to thank Buz Brock, Steve Carpenter, Toby Elmhirst, Chris Stokes, Victor Galaz, and Terry Iverson for their ideas and insights. Terry Hughes, Steve Carpenter, and Tom Brewer reviewed earlier versions of the manuscript. We also thank the reviewers for their suggestions and comments.

\section{LITERATURE CITED}

Adger, W. N., H. Eakin, and A. Winkels. 2009. Nested and teleconnected vulnerabilities to environmental change. Frontiers in Ecology and the Environment 7:150-157.

Anderies, J. M., A. A. Rodriguez, M. A. Janssen, and O. Cifdaloz. 2007. Panaceas, uncertainty, and the robust control framework in sustainability science. Proceedings of the National Academy of Sciences 104:15194-15199.

Battisti, D. S., and R. L. Naylor. 2009. Historical warnings of future food insecurity with unprecedented seasonal heat. Science 323:240-244.

Beattie, A. 2008. Rush to restrict trade in basic foods. Financial Times. In Depth: The Global Food Price Crisis. 1 April 2008.

Berger, L., R. Speare, P. Daszak, D. E. Green, A. A. Cunningham, C. L. Goggin, R. Slocombe, M. A. Ragan, A. D. Hyatt, K. R. McDonald, H. B. Hines,
K. R. Lips, G. Marantelli, and H. Parkes. 1998. Chytridiomycosis causes amphibian mortality associated with population declines in the rain forests of Australia and Central America. Proceedings of the National Academy of Sciences 95:9031-9036.

Biggs, R., S. R. Carpenter, and W. A. Brock. 2009. Turning back from the brink: detecting an impending regime shift in time to avert it. Proceedings of the National Academy of Sciences 106:826-831.

Brinkman, H.-J., S. de Pee, I. Sanogo, L. Subran, and M. W. Bloem. 2009. High food prices and the global financial crisis have reduced access to nutritious food and worsened nutritional status and health. The Journal of Nutrition doi: 10.3945/ jn.109.110767.

Brunnermeier, M. 2009. Deciphering the liquidity and credit crunch of 2007-2008. Journal of Economic Perspectives 23:77-100.

Buldyrev, S. V., R. Parshani, G. Paul, H. E. Stanley, and S. Havlin. 2010. Catastrophic cascade of failures in interdependent networks. Nature 464:1025-1028.

Carpenter, S. R., and W. A. Brock. 2006. Rising variance: a leading indicator of ecological transition. Ecology Letters 9:311-318.

Chapin, F. S., S. R. Carpenter, G. P. Kofinas, C. Folke, N. Abel, W. C. Clark, P. Olsson, D. M. S. Smith, B. Walker, O. R. Young, F. Berkes, R. Biggs, J. M. Grove, R. L. Naylor, E. Pinkerton, W. Steffen, and F. J. Swanson. 2010. Ecosystem stewardship: sustainability strategies for a rapidly changing planet. Trends in Ecology \& Evolution 25:241-249.

Cioccio, L., and E. J. Michael. 2007. Hazard or disaster: tourism management for the inevitable in Northeast Victoria. Tourism Management 28:1-11.

Comfort, L. K. 2005. Risk, security and disaster management. Annual Review of Political Science $8: 335-356$.

Criss, R. E., and E. L. Shock. 2001. Flood enhancement through flood control. Geology 29:875-878. 
Dakos, V., E. H. van Nes, R. Donangelo, H. Fort, and M. Scheffer. 2010 Spatial correlation as leading indicator of catastrophic shifts. Theoretical Ecology 3:163-174.

Folke, C., T. Hahn, P. Olsson, and J. Norberg. 2005. Adaptive governance of social-ecological systems. Annual Review of Environment and Resources 30:441-473.

Food and Agricultural Organization (FAO). 2010. Price volatility in agricultural markets. Economic and Social Perspectives, Policy Brief No. 12. Food and Agricultural Organization of the United Nations, Rome, Italy. [online] URL: http://www.fao. org/docrep/013/am053e/am053e00.pdf.

Fraser, C., C. A. Donnelly, S. Cauchemez, W. P. Hanage, M. D. Van Kerkhove, T. D. Hollingsworth, J. Griffin, R. F. Baggaley, H. E. Jenkins, E. J. Lyons, T. Jombart, W. R. Hinsley, N. C. Grassly, F. Balloux, A. C. Ghani, N. M. Ferguson, A. Rambaut, O. G. Pybus, H. Lopez-Gatell, C. M. AlpucheAranda, I. B. Chapela, E. P. Zavala, D. M. E. Guevara, F. Checchi, E. Garcia, S. Hugonnet, C. Roth, and The WHO Rapid Pandemic Assessment Collaboration. 2009. Pandemic potential of a strain of Influenza A (H1N1): early findings. Science 324:1557-1561.

Galaz, V., B. Crona, T. Daw, O Bodin, M. Nystrom, and P. Olsson. 2010. Can web crawlers revolutionize ecological monitoring? Frontiers in Ecology and the Environment 8:99-104.

Garber, K. 2008. How countries worsen the food price crisis. US News and World Report. 9 April 2008. [online] URL: www.usnews.com/articles/news/ world/2008/04/09/how-countries-worsen-the-foodprice-crisis.html.

Headey, D., and S. G. Fan. 2008. Anatomy of a crisis: the causes and consequences of surging food prices. Agricultural Economics 39:375-391.

Held, H., and T. Kleinen. 2004. Detection of climate system bifurcations by degenerate fingerprinting. Geophysical Research Letters 31:23.

Intergovernmental Panel on Climate Change (IPCC). 2007. Climate change 2007: synthesis report. Contribution of Working Groups I, II and III to the Fourth Assessment Report of the Intergovernmental Panel on Climate Change. Core
Writing Team, R. K. Pachauri, and A. Reisinger, editors. IPCC, Geneva, Switzerland.

International Telecommunications Union. 2009. The world in 2009: ICT facts and figures. ITU, Geneva, Switzerland. [online] URL: http://www.itu. int/ITU-D/ict/material/Telecom09 flyer.pdf.

International Rice Research Institute (IRRI). 2010. World export prices of rice, wheat and maize 1961-2009. IRRI, Manila, Philippines. [online] URL: http://beta.irri.org/solutions/index.php?option= com content\&task=view\&id=250.

Ives, A. R. 1995. Measuring resilience in stochastic systems. Ecological Monographs 65:217-233.

Janssen, M. A., J. M. Anderies, and B. H. Walker. 2004. Robust strategies for managing rangelands with multiple stable attractors. Journal of Environmental Economics and Management 47:140-162.

Ludwig, D., D. D. Jones, and C. S. Holling. 1978. Qualitative analysis of insect outbreak systems. Journal of Animal Ecology 47:315-332.

McCawley, P. 2009. Mass poverty in Asia: the impact of the global financial crisis. Policy brief for the Lowy Institute for International Policy, Sydney, Australia. [online] URL: http://www.lowyinstitute. org/Publication. asp?pid=1069.

McGeoch, M. A., S. H. M. Butchart, D. Spear, E. Marais, E. J. Kleynhans, A. Symes, J. Chanson, and M. Hoffmann. 2010. Global indicators of biological invasion: species numbers, biodiversity impact and policy responses. Diversity and Distributions 16:95-108.

Millennium Ecosystem Assessment (MA). 2005. Ecosystems and human well-being: synthesis. Island Press, Washington, D.C., USA.

Minnich, R. A. 2001. An integrated model of two fire regimes. Conservation Biology 15:1549-1553.

Mitchell, D. 2008. A note on rising food prices. Policy Research Working Paper 4682. Development Prospects Group, the World Bank, Washington, D. C., USA. [online] URL: http://econ.tu.ac.th/class/a rchan/RANGSUN/EC\%20460/EC\%20460\%20Readings/ Global\%20Issues/Food\%20Crisis/Food\%20Price/A\% 20Note\%20on\%20Rising\%20Food\%20Price.pdf. 
Murphy, B. F., and B. Timbal. 2008. A review of recent climate variability and climate change in southeastern Australia. International Journal of Climatology 28:859-879.

Orr, J. C., V. J. Fabry, O. Aumont, L. Bopp, S. C. Doney, R. A. Feely, A. Gnanadesikan, N. Gruber, A. Ishida, F. Joos, R. M. Key, K. Lindsay, E. MaierReimer, R. Matear, P. Monfray, A. Mouchet, R. G. Najjar, G.-K. Plattner, K. B. Rodgers, C. L. Sabine, J. L. Sarmiento, R. Schlitzer, R. D. Slater, I. J. Totterdell, M.-F. Weirig, Y. Yamanaka, and A. Yool. 2005. Anthropogenic ocean acidification over the twenty-first century and its impact on calcifying organisms. Nature 437:681-686.

Ostrom, E. 2007. A diagnostic approach for going beyond panaceas. Proceedings of the National Academy of Sciences 104:15181-15187.

Ostrom, E. 2010. A multi-scale approach to coping with climate change and other collective action problems. Solutions: For a Sustainable and Desirable Future 1(2):27-36. [online] URL: http:// www.thesolutionsjournal.com/node/565.

Ostrom, V., C. M. Tiebout, and R. Warren. 1961. The organization of government in metropolitan areas: a theoretical inquiry. American Political Science Review 55:831-842.

Pahl-Wostl, C. 2006. The importance of social learning in restoring the multifunctionality of rivers and floodplains. Ecology and Society 11(1): 10. [online] URL: http://www.ecologyandsociety.org/voll1/ iss1/art10/.

Pengelly, S., and G. Fishburn. 2002. Land, water and people: complex interactions in the Murrumbidgee river catchment, New South Wales, Australia. Pages 395-415 in P. M. Haygarth and S. C. Jarvis, editors. Agriculture, hydrology, and water quality. CAB International, Wallingford, UK.

Peters, D. P. C., P. M. Groffman, K. J. Nadelhoffer, N. B. Grimm, S. L. Coffins, W. K. Michener, and M. A. Huston. 2008. Living in an increasingly connected world: a framework for continental-scale environmental science. Frontiers in Ecology and the Environment 6:229-237.

Rockström, J., W. Steffen, K. Noone, A. Persson, F. S. Chapin, III, E. F. Lambin, T. M. Lenton, M. Scheffer, C. Folke, H. J. Schellnhuber, B. Nykvist,
C. A. de Wit, T. Hughes, S. van der Leeuw, H. Rodhe, S. Sörlin, P. K. Snyder, R. Costanza, U. Svedin, M. Falkenmark, L. Karlberg, R. W. Corell, V. J. Fabry, J. Hansen, B. Walker, D. Liverman, K. Richardson, P. Crutzen, and J. A. Foley. 2009. A safe operating space for humanity. Nature 461:472-475.

Scheffer, M., J. Bascompte, W. A. Brock, V. Brovkin, S. R. Carpenter, V. Dakos, H. Held, E. H. van Nes, M. Rietkerk, and G. Sugihara. 2009. Earlywarning signals for critical transitions. Nature 461:53-59.

United Nations Development Programme (UNDP). 2010. Human development report 2010 - the real wealth of nations: pathways to development. United Nations Development Programme, New York, New York, USA.

van Nes, E. H., and M. Scheffer. 2007. Slow recovery from perturbations as a generic indicator of a nearby catastrophic shift. Amateur Naturalist 169:738-747.

van Praag, C. M. 2003. Business survival and success of young small business owners. Small Business Economics 21:1-17.

Vespignani, A. 2009. Predicting the behavior of techno-social systems. Science 325:425-428.

Weir, L., and E. Mykhalovskiy. 2006. The geopolitics of public heath surveillance in the twenty-first century. In A. Bashford, editor. Medicine at the border: disease, globalization and security, 1850 to the present. Palgrave Macmillan, New York, New York, USA.

Wolf, M. 2009. The recession tracks the great depression. Financial Times. 16 June 2009.

World Bank. 2009. Global monitoring report 2009: a development emergency. The International Bank for Reconstruction and Development, The World Bank, Washington, D.C., USA. [online] URL: http ://siteresources.worldbank.org/INTGLOMONREP2009/ Resources/5924349-1239742507025/GMR09 book. pdf.

World Bank. 2010. World development report 2010: development and climate change. The International Bank for Reconstruction and Development, The World Bank, Washington, D.C., USA. 
World Resources Institute (WRI). 2008. World resources 2008: roots of resilience: growing the wealth of the poor. World Resources Institute, Washington, D.C., USA.

World Tourism Organization. 2008. Demand remains firm despite uncertainties. World Tourism Barometer. World Tourism Organization, Madrid, Spain. [online] URL: http://www.tourismroi.com/C ontent Attachments/27670/File 633513750035785076. pdf.

Yngve, A., B. Margetts, R. Hughes, and M. Tseng. 2009. Food insecurity - not just about rural communities in Africa and Asia. Public Health Nutrition 12:1971-1972.

Young, O. R., F. Berkhout, G. C. Gallopin, M. A. Janssen, E. Ostrom, and S. van der Leeuw. 2006. The globalization of socio-ecological systems: an agenda for scientific research. Global Environmental Change 16:304-316. 